\title{
ANALYSIS AND SYNTHESIS OF MODEL REFERENCE CONTROLLER FOR VARIABLE SPEED WIND GENERATORS INERTIAL SUPPORT
}

\author{
Elvisa Bećirović ${ }^{*}$ - Jakub Osmić ${ }^{* *}$ \\ - Mirza Kušljugić ${ }^{* *}$ - Nedjeljko Perić ${ }^{* * *}$
}

\begin{abstract}
Model Reference Controller (MRC) for contribution of Variable Speed Wind Generators (VSWG) in inertial response of Electrical Power System (EPS) is presented and analyzed in this paper. MRC is synthesized based on a model of Generating Unit With non-Reheat Steam Turbine (GUNRST) thus enabling VSWG to emulate GUNRST response during the initial stage of dynamic frequency response ie inertial phase. Very important property of conventional steam generating units is that its contribution to inertial phase response is independent from the initial generating power. By using MRC in VSWG it is accomplished that in most common wind speed region $(3-12 \mathrm{~m} / \mathrm{s})$ VSWG inertial support is almost independent from wind speed. Since in most EPSs VSWG replaces conventional steam generators, application of MRC algorithm provides that the characteristics of EPS in terms of inertial response are preserved, regardless of the growing trend of introducing VSWG. Evaluation analysis of the proposed MRC is performed on modified nine bus power system when VSWG with MRC is connected to one of the power system buses.
\end{abstract}

K e y w or d s: wind generator, inertial support, model reference controller

\section{INTRODUCTION}

The increase of variable speed wind generators (VSWG) in electrical power system (EPS) brings their system operation support possibilities to primary focus of interest. In order to maintain the safety and integrity of a power system, and also to maintain the frequency value within allowable range limit, continuous balance of generation and consumption is of a vital importance. Grid codes of different countries are continuously revised and their requirements are adjusted to the needs of possible participation of wind power plants in control of power system response during disturbances. Evaluation of impact assessment of wind power plants on EPS is especially important in isolated island systems [1]. Additionally, with the increase of integration rate of wind power plants the issues related to their impact on power system operation also becomes important in large interconnections.

Modern EPS with integrated wind power plants implies changes in the EPS structure since wind power plants replace conventional generating units, mainly conventional thermal power plants $[2,3]$. Since inertia of VSWG is partially or fully decoupled from power system via electronic converter, the total power system inertia is decreased. In order to provide the inertial support of modern VSWG, several different control concepts have been proposed which can be generally grouped into: inertial control, droop control, de-loading control or their combination [4-15]. Main challenge in VSWG inertial (and droop) control is "shaping" of the response of active power delivered to the rest of the EPS as well as the speed recovery of the VSWG after the frequency disturbance. This paper presents a MRC concept that provides VSWG to "behave" as the conventional generating unit with nonreheat steam turbine (GUNRST) in the first seconds after an active power disturbance [16]. This approach provides that regardless of the higher participation of VSWG in EPS its capability in frequency stabilization during first several seconds after the power system disturbances are preserved. Further, with the proposed MRC concept it is provided that VSWG truly emulates the behavior of the conventional steam generators since inertial support, in most common wind speed region $(3-12 \mathrm{~m} / \mathrm{s})$, is almost independent from the wind speed hence from the initial mechanical power of wind turbine, which is very important characteristics of the conventional steam turbines.

\section{BACKGROUND}

Large disturbances in EPS have consequences in significant and long term unbalances of active and/or reactive power. The emergence of unbalances of generation and consumption of reactive power results in voltage phasor module fluctuations, while the frequency fluctuations arise in the case of active power unbalance. Generator responses in the case of frequency changes due to the active power unbalance depends on generator type and its role in EPS. When long term active power unbalance occurs (ie loss of generator or sudden load changes) the equilibrium of generation and consumption is lost. In the case that mechanical power is lower than electrical power of

\footnotetext{
* EPC Elektroprivreda BiH d.d. Sarajevo, Vilsonovo šetalište 15, 71000 Sarajevo, Bosnia and Herzegovina (corresponding author), e.becirovic@elektroprivreda.ba, ${ }^{* *}$ University of Tuzla, Faculty of Electrical Engineering, Franjevačka 2, 75000 Tuzla, Bosnia and Herzegovina, jakub.osmic@untz.ba, mirza.kusljugic@untz.ba, ${ }^{* * *}$ Faculty of Electrical Engineering and Computing, Unska 3, 10000 Zagreb, Croatia, nedjeljko.peric@fer.hr
} 
the generator, rotor speed tends to decelerate. Dynamics of the rotor speed changes is defined in accordance with the following (swing) equation

$$
2 H \frac{\mathrm{d} \omega}{\mathrm{d} t}=P_{m}-P_{e}
$$

where $\omega$ is the rotational speed, $H$ is the inertia constant, $P_{m}$ and $P_{e}$ are the mechanical turbine power and electrical power of the synchronous generator.

Main indices of frequency response are analyzed in paper [2]. Inertia of synchronous generators plays an important part in power system stability. The inertia constants of conventional synchronous generators are in the order of 2-9 seconds [12]. In fact it can be said that power system inertia determines its frequency sensitivity and indicates how fast the system frequency deviates after a disturbance occurrence. Synchronous generators naturally contribute to the EPS inertia, where the inertial response of these is not controllable and is not a function of loading.

Today the most common types of modern large power wind generators are VSWG, such as double fed induction generators (DFIG) and fully rated converter wind turbine (FRCWT). Since DFIG and FRCWT use fast electronic converters (AC/DC/AC) and operate at MPPT (Maximum Power Point Tracking), no (or minimal) direct coupling exists between grid frequency deviation and their active power generation. By using the appropriate control algorithms this issue of "decoupling" might be overcome due to the fact that significant amount of kinetic energy is stored in the rotating turbine blades with typical inertia constants in the range of $2-6$ seconds $[1,9,12]$.

The inertial control approach enables transformation of a fraction of VSWG kinetic energy into electrical power, which is "instantaneously" delivered to the EPS by the (fast) electronic power converter. The time constant of the electronic converter is of the milliseconds order. The transformation of kinetic energy to electric power causes a VSWG speed decrease, which must be limited in order to prevent the turbine speed reaching its minimum permitted level. In addition, since VSWGs normally operate at MPPT, wind generator speed should be recovered to this optimum value after the frequency stabilization. Since VSWGs normally operate without spinning reserve, speed recovery is performed by VSWG delivering less active electric power than optimum (maximum available). This ensures that speed of a VSWG recovers to its optimum value (for the constant wind speed case to the value before the frequency transient).

In order to analyze power system requirements and the impact of wind power control capability on power systems, simulation studies must be performed on a power system model including a VSWG model. In this paper, the Generic Wind Turbine Control Model (GWTCM) is used referring to a dynamic model whose parameters can be adjusted to represent similar control systems from different manufacturers [17]. A GWTCM is not a general purpose model of wind turbine control systems. It is intended mainly for bulk power system studies that are conducted in positive-sequence simulation platforms such as
PSLF or PSS/E [17,18-21]. Development of a GWTCM is an ongoing process and over the years details used in GWTCM have changed as a result of the work of different contributors. One of the first significant impacts on the development of GWTCM is presented in [18]. Initial ideas for generic models for different types of Wind Turbine Generator (WTG) technologies were also published by CIGRE [19]. Currently, two major groups are working towards improvements of generic models of WTG technologies: the Western Electricity Coordinating Council (WECC Renewable Energy Modeling Task Force) and the International Electrotechnical Commission (IEC Technical Committee TC 88, Working Group 27) [20]. In this paper focus has been put on a GE 3.6 MW GWTCM presented in $[17,21]$. This model can easily be applied to the other types of GE wind turbines by changing parameters of the GWTCM [20]. A GWTCM block diagram without reactive power control (that is completely decoupled from active power control) is presented in Fig. 1, where $V$ represents the bus voltage at the point of VSWG connection and it is assumed that $V=1$. This is not a strict assumption since the control system of electronic converter of VSWG regulates the bus voltage. Wind power model given on Fig. 1 is calculated from the following equation

$$
P_{m}=\frac{\rho}{2} A_{r} v_{w}^{3} C_{p}(\lambda, \theta)
$$

as in [17], where $P_{m}$ is the mechanical power extracted from wind (p.u), $\rho$ is the air density $\left(\mathrm{kg} / \mathrm{m}^{3}\right), A_{r}$ is the area swept by rotor blades $\left(\mathrm{m}^{2}\right)$, and $v_{w}$ is the wind speed $(\mathrm{m} / \mathrm{s}) . C_{p}$ represents the power coefficient that is a strongly nonlinear function of pitch angle $\theta$ (deg) and the ratio of the rotor blade tip speed and the wind speed. The equation for calculation of $C_{p}$ given in [17] is

$$
C_{p}(\theta, \lambda)=\sum_{i=0}^{4} \sum_{j=0}^{4} \alpha_{i, j} \lambda^{j} \theta^{i}, \quad \lambda=K_{b} \frac{\omega}{v_{w}}
$$

where $\lambda$ is the tip speed ratio, $\omega$ being the turbine rotational speed in $(\mathrm{pu})$ and $K_{b}$ is a constant whose value depends on the type of WTG used. Parameters $\alpha_{i, j}$ are given in Table 1.

\section{DEVELOPMENT OF MODEL REFERENCE CONTROLLER OF VSWG}

A simplified generic block diagram of conventional generating unit that can be used to analyze its dynamic responses is presented in Fig. 2, [23]. Here $G_{g}$ is governor transfer function, $G_{t d c}$ is transfer function of transient droop compensation block typical for hydraulic generating unit, $G_{t}$ is turbine transfer function, $H$ is inertia constant of rotating parts of generating unit, $R$ is droop constant, and $D$ models variation of load with grid frequency variation. According to (1), with

$$
\Delta P_{m}=-\frac{1}{R} G_{g} G_{t} \Delta \omega, \quad \Delta P_{a}=2 H s \Delta \omega,
$$






Fig. 1. VSWG model (without reactive power control)

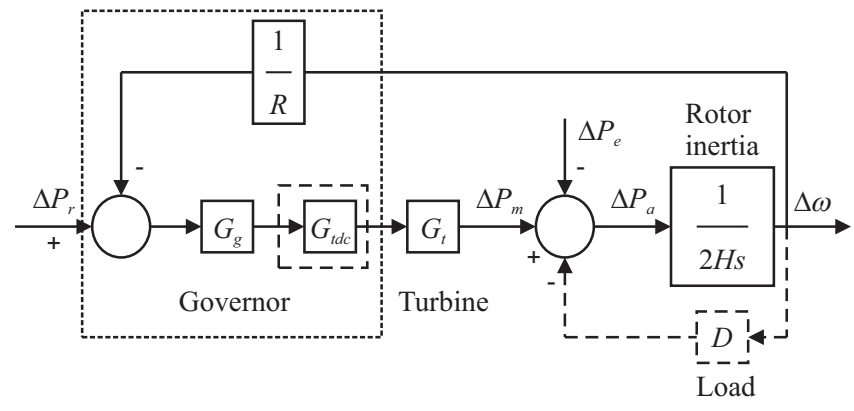

Fig. 2. Generic block diagram of conventional power unit used in frequency stability studies

the following equation for active electric power can be delivered

$$
\Delta P_{e}=-2 H s \Delta \omega-\frac{1}{R} G_{g} G_{t} \Delta \omega
$$

Since an ideal derivation of signal in (7) cannot be achieved it should be replaced by filtered derivation of frequency deviation as in (1)

$$
\begin{gathered}
\Delta P_{e}=-\frac{2 H s}{\tau_{B} s+1} \Delta \omega-\frac{1}{R} G_{g} G_{t} \Delta \omega=-\frac{2 H s}{\left(s / \omega_{B}\right)+1} \Delta \omega \\
-\frac{1}{R} G_{g} G_{t} \Delta \omega=-G_{i} \Delta \omega-G_{m} \Delta \omega .
\end{gathered}
$$

As given in $(8), \omega_{B}=1 / \tau_{B}$ where $\omega_{B}$ is bandwidth of the first order time lag (low pass filter) with transfer function $1 /\left(\tau_{B} s+1\right)$. The filter bandwidth $\omega_{B}$ should be large enough to preserve useful information in signal $\Delta \omega$. Also, a signal noise in $\Delta \omega$ should be filtered adequately. In this paper the value $\omega_{B}=15$ is proposed. In order to enable the VSWG to participate in frequency support during transient process, after a sudden active power disturbance, it is necessary to define a proper control algorithm. The basic idea of the proposed MRC is to force VSWG to behave as close as possible to reference GUNRST within inertial phase of the frequency response (0-5 seconds after disturbance). This approach ensures that during the initial phase of frequency transients power system with VSWG behaves similarly as power system with GUNRST connected at the same point of EPS. It is assumed that reference GUNRST has the same inertia constant and nominal active power as VSWG. The goal of a wind turbine control system is to work in a MPPT and therefore it has no spinning reserve. Due to this fact, it is not possible to exactly realize the control law given by (7). The first term in (8) (inertial power) converge to zero as time goes to infinity since it includes $s$ in its numerator. The second term in (8) converges to $1 / R\left[\operatorname{dcgain}\left(G_{g} G\right) \Delta \omega_{s s}\right]$ as time goes to infinity, where $\Delta \omega_{s s}$ is steady state frequency deviation. To solve this problem a term that has the same static gain as term $\frac{1}{R} G_{g} G_{t} \Delta \omega$ is added to the right hand side of (8).

By adding this term, the behavior of (8) in frequency transient process should not be changed significantly, but it must force right hand side of (8) to converge to zero with a desirable time constant $\tau$, as time increases to infinity. The following additional term is proposed in this paper

$$
G a d=\frac{1 / R}{(\tau s+1)} G_{g} G_{t}
$$

Model reference control algorithm is accordingly based on the following control law

$$
\begin{gathered}
\Delta P_{e 1}=-\frac{2 H s}{\tau_{B} s+1} \Delta \omega-\frac{1}{R} G_{g} G_{t} \Delta \omega+\frac{1 / R}{(\tau s+1)} G_{g} G_{t} \Delta \omega \\
=-\frac{2 H s}{\tau_{B} s+1} \Delta \omega-\frac{1}{R} \frac{\tau s}{\tau s+1} G_{g} G_{t} \Delta \omega \\
=-G_{i} \Delta \omega-G_{m m} \Delta \omega .
\end{gathered}
$$




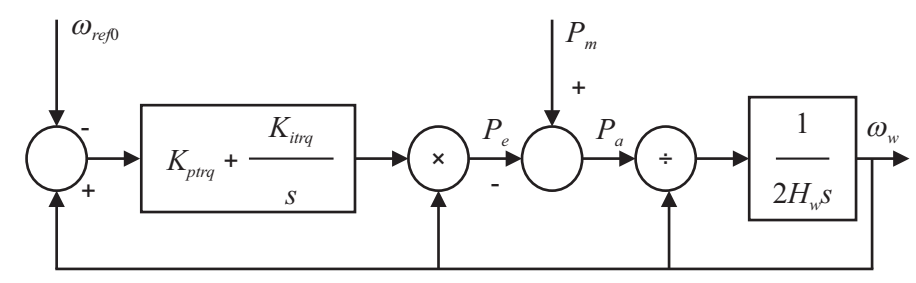

Fig. 3. Simplified block diagram of control system of VSWG

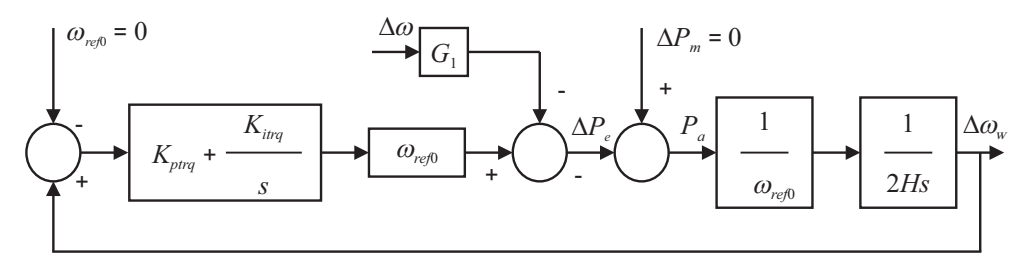

Fig. 4. Linearized control structure of VSWG for frequency control support from Fig. 3

Equation (10) indicates that second term $G_{m m}$ of the proposed control law also converges to zero since it has $s$ in its numerator. When comparing the equations (10) and (8) it can be seen that the second term $G_{m m}$ in (10) differs from the second term $G_{m}$ in (8) in the dipole

$$
G_{d}=\frac{\tau s}{\tau s+1} .
$$

Its pole value is $s_{p}=-1 / \tau$, so if $\tau$ is chosen as sufficiently large then the pole of dipole (11) is very close to its zero $s_{z}=0$. Multiplication of a transfer function with a dipole slightly changes the response of the transfer function in transient process whilst the behavior of a transfer function at steady state can be substantially changed.

In order to provide the MPPT control strategy for wind speeds between $3 \mathrm{~m} / \mathrm{s}$ and $12 \mathrm{~m} / \mathrm{s}$, the pitch control loop keeps the zero pitch angle value. Also, during the inertial phase of dynamic response it is usually assumed that wind speed remains unchanged [17]. Values of time constants $T_{p c}$ and $T_{c o n}$ are on milliseconds order and can be neglected in terms of time range of inertial response (approximately $5 \mathrm{~s}$ ). So, the first order blocks in Fig. 1. with time constants $T_{p c}$ and $T_{c o n}$ can be replaced with constant gain blocks for synthesis purposes of the MRC. Common value of time constant $T_{p e}$ is $60 \mathrm{~s}$ which is much greater when comparing it with the duration of inertial phase of dynamic response. Consequently, quite precise assumption during the inertial stage of dynamic frequency response is that $\omega_{r e f}=\omega_{\text {ref } 0}=$ const where $\omega_{r e f 0}$ refers to the wind turbine reference speed at the beginning of the inertial stage. By considering all the assumptions for the synthesis purpose of MRC, block diagram from Fig. 1. can be simplified as illustrated on Fig. $3[24,25]$. This block diagram is still nonlinear, due to the existence of signal multiplication and division. Since VSWG operate at the MPPT during predisturbance steady state, VSWG speed is optimal. At the vicinity of the optimal VSWG speed, characteristics speed ratio $(\lambda)$ vs captured mechanical power $\left(P_{m}\right)$ is somewhat flat when comparing it within other regions of this characteristics. Additionally, it is assumed that since frequency transient process is relatively short, wind speed will not considerably change during this process. Consequently, captured mechanical power of VSWG can be regarded as constant during frequency transient process. Also, for the purpose of analysis and synthesis VSWG, speed signal entering block of multiplication and division can be treated as constant, ie $\omega_{w}=\omega_{r e f 0}=$ const. When signal variations around its equilibrium is used instead of absolute value of signals then linear model of the system, presented in Fig. 4, could be developed. A new control signal is added after multiplication of the signal leaving PI controller by actual wind speed. The block with transfer function $G_{1}$ in Fig. 4 represents the novel control algorithm. The input in this block is the grid frequency deviation $\Delta \omega$. In order to further simplify the analysis it is assumed that $H_{w}=H$.

Transfer function $G_{1}$ from Fig. 3, where $\Delta P_{e}=$ $-\Delta P_{a}$, should be chosen in the way that injected electrical power $\Delta P_{e}$ conforms to control law (10).

In Fig. 4 symbol $\Delta \omega$ represents deviation of the grid frequency. Transfer function from $\Delta \omega$ to $\Delta P_{e}$ is defined as

$$
\frac{\Delta P_{e}}{\Delta \omega}=-\frac{G_{1}}{\Delta}
$$

where $\Delta$ represents characteristic function of the system and it is given by

$$
\begin{aligned}
\Delta=1+\left(K_{p t r q}+\frac{K_{i t r q}}{s}\right) & \omega_{r e f 0} \frac{1}{\omega_{r e f 0}} \frac{1}{2 H s} \\
= & \frac{2 H s^{2}+K_{p t r q} s+K_{i t r q}}{2 H s^{2}}
\end{aligned}
$$

Substituting (13) into (12) gives

$$
\begin{aligned}
\frac{\Delta P_{e}}{\Delta \omega}=-\frac{\Delta P_{a}}{\Delta \omega}=-\frac{G_{1}}{\Delta} & =-\frac{2 H s^{2} G_{1}}{2 H s^{2}+K_{p t r q} s+K_{i t r q}} \\
& =-\frac{s^{2} G_{1}}{s^{2}+\frac{K_{p t r q}}{2 H} s+\frac{K_{i t r q}}{2 H}} .
\end{aligned}
$$

The poles of transfer function (9) are

$$
\Delta_{1 / 2}=-\frac{K_{p t r q}}{4 H} \pm \frac{1}{2} \sqrt{\left(\frac{K_{p t r q}}{2 H}\right)^{2}-\frac{4 K_{i t r q}}{2 H}} .
$$




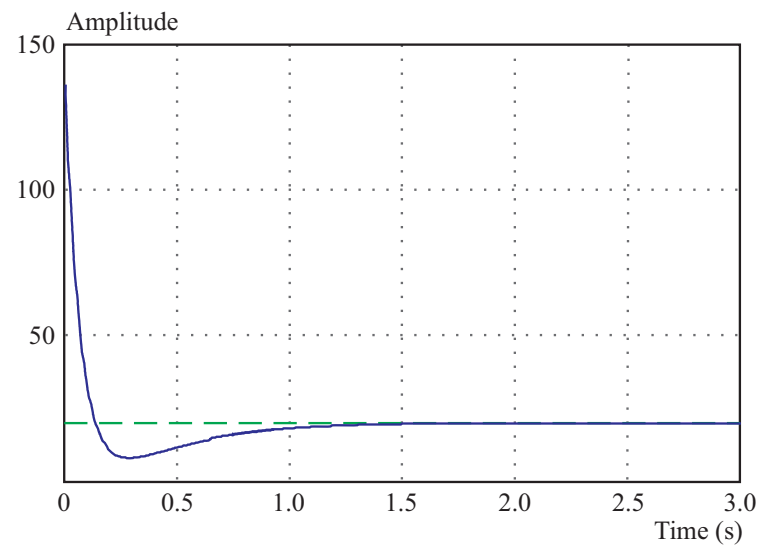

Fig. 5. Time responses of $\Delta P_{e}$ (solid line) and $\Delta P_{e 2}$ (dashed line) to unit step of $\Delta \omega$

If request of VSWG control system is that the fastest response to a step of $\Delta \omega_{\text {ref }}$, without overshoot, is achieved then parameters $K_{p t r q}$ and $K_{i t r q}$ of PI controller should be chosen so that poles (15) are real, negative end equal (the transfer function (14) must have double negative pole). The pole of the transfer function (14) is double providing that

$$
\Delta_{1 / 2}=-\frac{K_{p t r q}}{4 H}, \quad K_{i t r q}=\frac{\left(K_{p t r q}\right)^{2}}{8 H}
$$

Due to the integral part of PI controller, VSWG speed equals to the reference speed in steady state. By using (16) it follows

$$
\Delta P_{e}=-\frac{s^{2} G_{1}}{s^{2}+\frac{K_{p t r q}}{2 H} s+\frac{K_{i t r q}}{2 H}} \Delta \omega=-\frac{s^{2} G_{1}}{\left(s+\frac{K_{p t r q}}{4 H}\right)^{2}} \Delta \omega .
$$

In addition from Fig. 3

$$
\begin{aligned}
\Delta \omega_{w}=\frac{1}{\omega_{\text {refo }}} & \frac{1}{2 H s} \frac{G_{1}}{\Delta} \Delta \omega \\
& =\frac{1}{2 H \omega_{\text {ref } 0}} \frac{s G_{1}}{s^{2}+\frac{K_{\text {ptrq }}}{2 H} s+\frac{K_{\text {itrq }}}{2 H}} \Delta \omega .
\end{aligned}
$$

From (19) it follows that there is an inverse proportionality between VSWG speed deviation $\Delta \omega_{w}$ and initial wind speed $\omega_{r e f 0}$. From (18) it follows that $\Delta P_{e}$ in steady state diminishes due to existence of term $s^{2}$ in the numerator of transfer function. In addition, $\Delta \omega_{w}$ also goes to zero as time passes if there is no pole of $G_{1}$ at the origin of $s$ plane (that means there is no $s$ in denominator of $\left.G_{1}\right)$. This is due to existence of $s$ in the numerator of expression at the right hand side of (19). This way it is ensured that VSWG speed and electrical power of VSWG at steady state restore to the value before frequency disturbance. At the end of transient process, steady state frequency deviation becomes $\Delta \omega_{s s}$. From the above considerations it can also be concluded that, in order to achieve specified goals, the existence of term $s$ (ideal derivation) in numerator of $G_{1}$ is unnecessary $[24,25]$.

In order to achieve that VSWG emulates referenceGUNRST model it is necessary that expression on the right hand side of (18) equals expression on the right hand side of (10). This could be achieved only if $G_{1}$ includes integrator $1 / s$. In this case, however, according to the previous considerations, VSWG speed will not be restored to the value before frequency disturbance. Because of this it is necessary to make modification of the reference model (10). This can be performed by multiplying transfer function of the reference model with a dipole that includes $s$ in its numerator, without affecting reference model (10) during transient process. Then, the new reference model is described by

$$
\begin{gathered}
\Delta P_{e 2}=\frac{\tau_{1} s}{\tau_{1} s+1}\left(-\frac{2 H s}{\tau_{B} s+1}-\frac{1}{R} \frac{\tau s}{\tau s+1} G_{g} G_{t}\right) \Delta \omega \\
=\frac{\tau_{1} s^{2}}{\tau_{1} s+1} G_{r} \Delta \omega \\
G_{r}=-\frac{2 H}{\tau_{B} s+1}-\frac{1}{R} \frac{\tau}{\tau s+1} G_{g} G_{t}
\end{gathered}
$$

The transfer functions of the governor and turbine are chosen as

$$
G_{g}=\frac{1}{\tau_{g} s+1}, \quad G_{t}=\frac{1}{\tau_{t} s+1}
$$

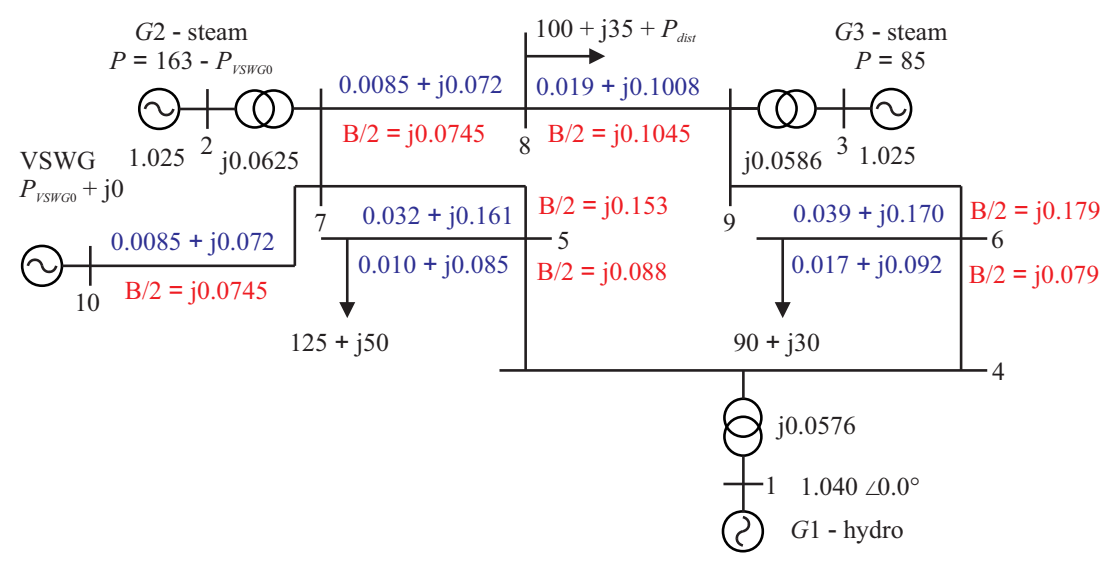

Fig. 6. Analyzed test system based on WSCC 9 bus test system 


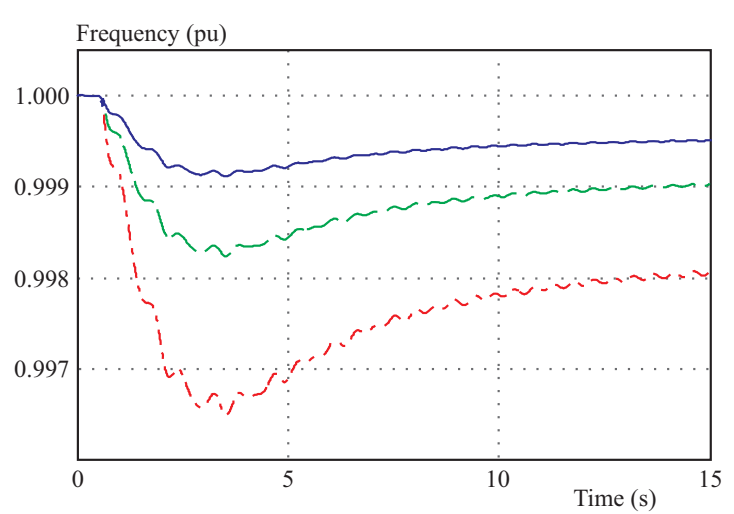

Fig. 7. Frequency response after active power disturbances of: 5 MW (solid line), $10 \mathrm{MW}$ (dashed line), $20 \mathrm{MW}$ (dash-dotted line)

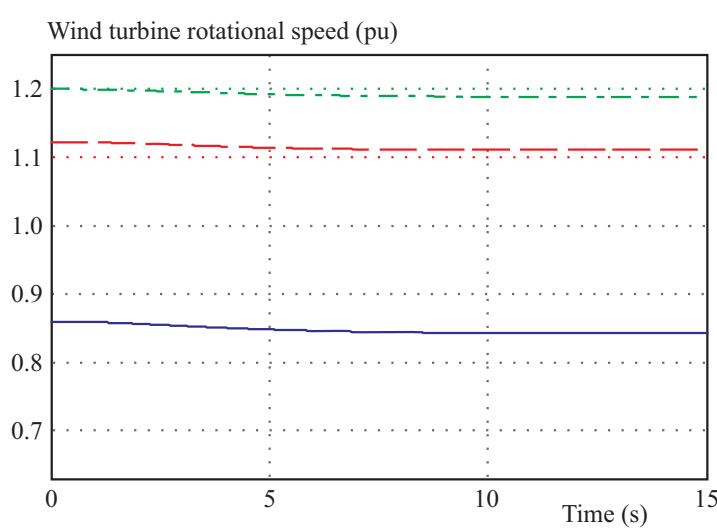

Fig. 9. Rotational speed of VSWG with MRC after power system disturbance of 0.1 p.u for different wind speed; $v_{w}=6 \mathrm{~m} / \mathrm{s}$ (solid line), $v_{w}=8 \mathrm{~m} / \mathrm{s}$ (dashed line), $v_{w}=10 \mathrm{~m} / \mathrm{s}$ (dash-dotted line)

where time constant of the governor $\tau_{g}=0.2$, turbine time constant is $\tau_{t}=0.3$, and droop constant is $R=0.04$ [23]. Time constant $\tau_{1}$ should be selected large enough to prevent changes of the new model transient behavior in comparison to the old one. In this paper the chosen value is that of $\tau_{1}=30 \mathrm{~s}$. Responses to the step input of the ideal reference model (7) and the model described by (20) are shown in Fig. 5. From there we can see that there is no substantial difference between the two responses in the first few seconds. To make the right hand side in (18) equal to the right hand side in (20) expression for $G_{1}$ must be

$$
\begin{gathered}
G_{1}=-\frac{\tau_{1}\left(s+\frac{K_{p t r q}}{4 H}\right)^{2}}{\tau_{1} s+1} G_{r}=\frac{2 H}{\tau_{B}} \frac{\left(s+\frac{K_{p t r q}}{4 H}\right)^{2}}{\left(s+\frac{1}{\tau_{1}}\right)\left(s+\frac{1}{\tau_{B}}\right)} \\
+\frac{1}{R} \frac{\left(s+\frac{K_{p t r q}}{4 H}\right)^{2}}{\left(s+\frac{1}{\tau_{1}}\right)\left(s+\frac{1}{\tau}\right)} G_{g} G_{t}=G_{i}^{\prime}+G_{m}^{\prime} .
\end{gathered}
$$

For values $H=5.23$ and $K=0.5$, the first term on the right hand side in (16) has a double zero $z_{1 / 2}=$ $-K_{p t r q} / 4 H=-0.019$ and poles $p_{1}=-1 / \tau_{1}=-0.033$ and $p_{2}=-1 / \tau_{B}=-\omega_{B}=-15$. The zero at -0.019 and the pole at -0.033 are quite slow (and very close to each

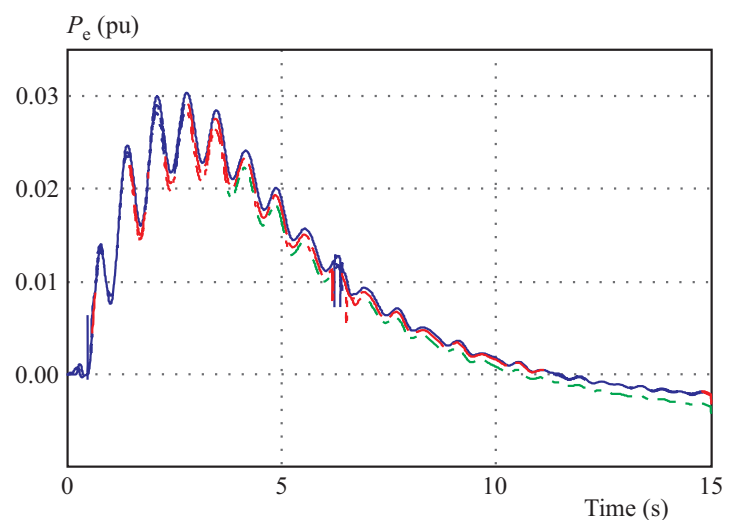

Fig. 8. Active power of VSWG with MRC after power system disturbance of $0.1 \mathrm{p} . \mathrm{u}$ for different wind speed; $v_{w}=6 \mathrm{~m} / \mathrm{s}$ ( line), $v_{w}=8 \mathrm{~m} / \mathrm{s}$ (dashed line), $v_{w}=10 \mathrm{~m} / \mathrm{s}$ (dash-dotted line)

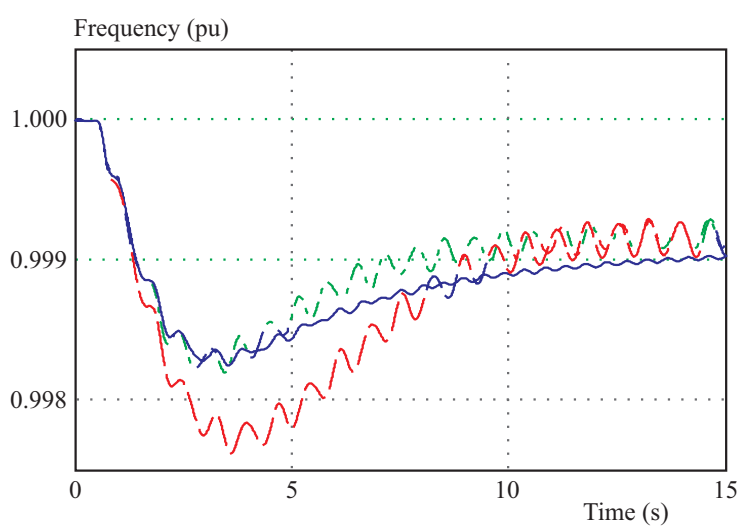

Fig. 10. Frequency response after active power disturbance of 0.1 p.u - comparison of VSWG with MRC (solid line), without inertial support (dashed line) and conventional GUNRST (dashdot line)

other) in comparison to the second pole. For this reason they can be cancelled so the first part of the transfer function can be simplified to

$$
G_{i i}^{\prime}=\frac{2 H}{\tau_{B}} \frac{s+\frac{K_{p t r q}}{4 H}}{s+1 / \tau_{B}}=\frac{K_{p t r q}}{2} \frac{\frac{4 H}{K_{p t r q}} s+1}{\tau_{B} s+1} .
$$

Regarding the position of its zeros and poles, transfer function $G_{i i}^{\prime}$ represents transfer function of a lead compensator. As expected duration of the overall transient process in EPS is about 30 seconds it follows that appropriate value of the time constant $\tau$ is $\tau=30-\tau_{g}-\tau_{t}=$ $30-\tau_{g}-\tau_{t}=29.5 \mathrm{~s}$. The second term on the right hand side of (23) has double zero $z_{1 / 2}=-K_{p t r q} / 4 H=-0.019$ and poles $p_{1}=-1 / \tau_{1}=-0.033$ and $p_{2}=-1 / \tau \approx p_{1}$. Since poles and zeros of the second term in (23) are very close; for the purposes of transient analysis they can be cancelled as well. This way transfer function of the second term in (23) can be simplified to

$$
G_{m m}^{\prime}=\frac{1}{R} G_{g} G_{t} .
$$

Accordingly, the transfer function $G_{1}$ (the proposed MRC) becomes

$$
G_{1}=\frac{K_{p t r q}}{2} \frac{\left(\frac{4 H}{K_{p t r q}} s+1\right)}{\tau_{B} s+1}+\frac{1}{R} G_{g} G_{t} .
$$


Table 1. $C_{p}$ Coefficients

\begin{tabular}{ccccc}
\hline$\alpha_{0,0}$ & $\alpha_{0,1}$ & $\alpha_{0,2}$ & $\alpha_{0,3}$ & $\alpha_{0,4}$ \\
$-4.1909 \times 10^{-1}$ & $2.1808 \times 10^{-1}$ & $-1.2406 \times 10^{-2}$ & $-1.3365 \times 10^{-4}$ & $1.1524 \times 10^{-5}$ \\
$\alpha_{1,0}$ & $\alpha_{1,1}$ & $\alpha_{1,2}$ & $\alpha_{1,3}$ & $\alpha_{1,4}$ \\
$-6.7606 \times 10^{-2}$ & $6.0405 \times 10^{-2}$ & $-1.3934 \times 10^{-2}$ & $1.0683 \times 10^{-3}$ & $-2.3895 \times 10^{-5}$ \\
$\alpha_{2,0}$ & $\alpha_{2,1}$ & $\alpha_{2,2}$ & $\alpha_{2,3}$ & $\alpha_{2,4}$ \\
$1.5727 \times 10^{-2}$ & $-1.0996 \times 10^{-2}$ & $2.1495 \times 10^{-3}$ & $-1.4855 \times 10^{-4}$ & $2.7937 \times 10^{-6}$ \\
$\alpha_{3,0}$ & $\alpha_{3,1}$ & $\alpha_{3,2}$ & $\alpha_{3,3}$ & $\alpha_{3,4}$ \\
$-8.6018 \times 10^{-4}$ & $5.7051 \times 10^{-4}$ & $-1.0479 \times 10^{-4}$ & $5.9924 \times 10^{-6}$ & $-8.9194 \times 10^{-8}$ \\
$\alpha_{4,0}$ & $\alpha_{4,1}$ & $\alpha_{4,2}$ & $\alpha_{4,3}$ & $\alpha_{4,4}$ \\
$1.4787 \times 10^{-5}$ & $-9.4839 \times 10^{-6}$ & $1.6167 \times 10^{-6}$ & $-7.1535 \times 10^{-8}$ & $4.9686 \times 10^{-10}$ \\
\hline \multicolumn{5}{c}{}
\end{tabular}

\section{EVALUATION OF THE PROPOSED MRC}

The nine bus system presented in [16], with the added bus VSWG (no. 10) to which a VSWG is connected, as shown in Fig. 6, is used as simulation example in the evaluation analysis of the proposed MRC. VSWG farm consists of 30 units each with rated power 3.6 MW. The VSWG model presented in [14] is used without any simplification (with reactive power control also included). Parameters of VSWG are given in Table 2. Since at the initial moment system load is assumed to be constant, the initial generation of active power from steam generator G2 is reduced by the amount of the VSWG active power generation $P_{V S W G 0}$. The initial wind speed of VSWG depends on this value. The network data and initial steady state data necessary for power flow calculations are presented in Fig. 6. Generator data, turbine data and governor, adopted from [16] and [23], are given in Table 3 and Table 4 . Simulations are performed by using dedicated models developed using Matlab and Simulink. After 0.5 seconds from starting the simulation, active power disturbances (load increase) of different amounts $5 \mathrm{MW}$, $10 \mathrm{MW}$ and $20 \mathrm{MW}$, respectively are injected into the bus 8 . The frequency responses of the EPS with VSWG inertial support after active power disturbance of $5 \mathrm{MW}$ (solid line), $10 \mathrm{MW}$ (dashed line) and $20 \mathrm{MW}$ (dashdotted line) is presented in Fig. 7. The VSWG active power and speed change for active power disturbance of $10 \mathrm{MW}$ and different initial wind speed of $v_{w}=6 \mathrm{~m} / \mathrm{s}$ (solid line), $v_{w}=8 \mathrm{~m} / \mathrm{s}$ (dashed line), $v_{w}=10 \mathrm{~m} / \mathrm{s}$ (dash-dotted line) are presented in Figs. 8 and 9, respectively. It can be seen that VSWG speed does not change significantly due to the relatively large inertia constant. Thus the contribution to frequency stabilization of the proposed MRC concept is verified and independence of its active power generation during the frequency transients from the initial wind speed is confirmed. Frequency response at bus 8 in case of active power disturbance of $10 \mathrm{MW}(0.1 \mathrm{p} . \mathrm{u})$ is given on Fig. 10 for three different cases: VSWG with MRC, GUNRST and VSWG with no inertial support control. As can be seen from Fig. 10, by using the inertial support frequency control, both the nadir and the rate of change of frequency are considerably decreased. Also, a VSWG with the proposed MRC concept has almost identical response as GUNRST during initial response stage (up to $5 \mathrm{~s}$ ). From Fig. 10 it is also possible to notice the stabilizing effect of VSWG on power system frequency oscillations.

Parameters and coefficients used in the simulations are in Tables 1-4.

Table 2. Parameters of the VSWG

\begin{tabular}{|c|c|c|c|c|c|}
\hline $\begin{array}{cc}K_{b} & K_{p p} \\
69.5 & 150 \\
\end{array}$ & $\begin{array}{c}K_{i p} \\
25 \\
\end{array}$ & $\begin{array}{c}K_{p c} \\
3 \\
\end{array}$ & $\begin{array}{c}K_{i c} \\
30 \\
\end{array}$ & $\begin{array}{c}K_{p t r q} \\
0.5 \\
\end{array}$ & $\begin{array}{c}K_{i t r q} \\
0.05 \\
\end{array}$ \\
\hline$T_{p e}$ & $T_{p c}$ & $T_{\text {con }}$ & $T_{p}(\mathrm{~s})$ & $H$ & $V(\mathrm{p} . \mathrm{u})$ \\
\hline 60 & 0.05 & 0.02 & 0.3 & 5.23 & 1 \\
\hline $\begin{array}{c}P_{\text {rated }} \\
\text { (p.u.) }\end{array}$ & $\begin{array}{l}P_{\max } \\
\text { (p.u.) }\end{array}$ & $\begin{array}{c}(\mathrm{d} P / \mathrm{d} t)_{\max } \\
(\text { p.u. } / \mathrm{s})\end{array}$ & $\begin{array}{c}(\mathrm{d} P / \mathrm{d} t)_{\min } \\
(\text { p.u. } / \mathrm{s})\end{array}$ & $\begin{array}{l}P_{\text {set }} \\
\text { (p.u.) }\end{array}$ & $\begin{array}{l}I_{\max } \\
\text { (p.u.) }\end{array}$ \\
\hline 1 & 1.12 & 0.45 & -0.45 & 1 & 1.1 \\
\hline$a_{2}$ & $a_{1}$ & $a_{0}$ & $\begin{array}{c}\beta_{\max } \\
\left({ }^{\circ}\right)\end{array}$ & $\begin{array}{c}(\mathrm{d} \beta / \mathrm{d} t)_{\max } \\
\left({ }^{\circ} / \mathrm{s}\right)\end{array}$ & $\begin{array}{c}(\mathrm{d} \beta / \mathrm{d} t)_{\min } \\
(\circ / \mathrm{s})\end{array}$ \\
\hline-0.75 & 1.59 & 0.63 & 27 & 10 & -10 \\
\hline
\end{tabular}

Table 3. Generator and turbine data adopted from [24]

\begin{tabular}{cccc}
\hline Generator & G1 & G2 & G3 \\
Rated MVA & 247.5 & 192.0 & 128.0 \\
Type & hydro & Steam & Steam \\
xd & 0.1460 & 0.8958 & 1.3125 \\
xd $^{\prime}$ & 0.0608 & 0.1198 & 0.1813 \\
H & 23.64 & 6.40 & 3.01 \\
D (damping) & 1 & 1 & 1 \\
\hline
\end{tabular}

Note: reactance values in pu on a 100 MVA base

Table 4. Turbine and Governor parameters

\begin{tabular}{cc}
\hline$T_{G}(\mathrm{~s})$ & 0.2 \\
$T_{R}(\mathrm{~s})$ & 5 \\
$R_{T}$ & 0.38 \\
$R_{P}$ & 0.05 \\
$T_{w}(\mathrm{~s})$ & 1 \\
\hline
\end{tabular}

\section{CONCLUSIONS AND FUTURE WORK}

The proposed control algorithm based on MRC confirmed the possibility of the participation of VSWG in primary frequency control and its participation in the inertial stage of dynamic frequency response. The practice is that wind power integration into conventional power system replaces the thermal power plants, thus simultaneously decreasing the total inertia of the system. Using the proposed MRC it is achieved that VSWG response "truly" emulates the behavior of conventional thermal power plants without reheat during the inertial response. VSWG with the proposed MRC has an important property that its inertial support is not dependent on the initial wind speed (ie initial mechanical power), which is identical to the property of the conventional steam units with synchronous generators. The stabilizing effect of a VSWG with MRC on power system frequency oscillations provides that VSWG with MRC holds even better properties in this aspect. In the future it is planned to evaluate characteristics of the proposed MRC on a realistic power system. 


\section{REFERENCES}

[1] WANG, Y.-DELILLE, G.-BAYEM, H.-GUILLAUD, X.FRANCOIS, B.: High Wind Power Penetration in Isolated Power Systems-Assessment of Wind Inertial and Primary Frequency Responses, IEEE Trans. Power Systems 28 No. 3 (Aug 2013), 2412-2420.

[2] ALtiN, M.: Dynamic Frequency Response of Wind Power Plants, PhD thesis, Aalborg University, Department of Energy Technology Aalborg, Denmark, November 2012.

[3] ANAYA-LARA, O.-JENKINS, N.-EKANAYAKE, J.CARTWRIGHT, P.-HUGHES, M.: Wind Energy Generation - Modeling and Control, Willey, West Sussex, U.K., 2009.

[4] HUGHES, F. M.-ANAYA-LARA, O.-JENKINS, N.-STRBAC, G. : Control of DFIG-Based Wind Generation for Power Network Support, IEEE Trans. Power Systems 20 No. 4 (Nov 2005), 1958-1966.

[5] MORREN, J.- de HAAN, S. W. H.-KLING, W. L.-FERREIRA, J. A. : Wind Turbines Emulating Inertia and Supporting Primary Frequency Control, IEEE Trans. Power Systems 21 No. 1 (Feb 2006), 433-434.

[6] MULJADI, E.-GEVORGIAN, V.-SINGH, M.-SANTOSO, S.: Understanding Inertial and Frequency Response of Wind Power Plants, Preprint, IEEE Symposium on Power Electronics and Machines in Wind Applications, Denver, Colorado, July 16-18, 2012.

[7] WANG-HANSEN, M.-JOSEFSSON, R.-MEHMEDOVIC, H. : Frequency Controlling Wind Power Modeling of Control Strategies, Sustainable Energy, IEEE Transactions on 4 No. 4 (Oct 2013), 954-959.

[8] RAMTHARAN, G.-EKANAYAK, J. B.-JENKINS, N. : Frequency Support from Doubly Fed Induction Generator Wind Turbines, IET Renewable Power Generation 1 (Mar 2007), 3-9.

[9] Ullah, N. R.-THIRINGER, T.-KARLSSON, D.: Temporary Primary Frequency Control Support by Variable Speed Wind Turbines - Potential and Applications, IEEE Trans. Power Systems 23 No. 2 (May 2008), 601-612.

[10] CONROY, J. F.-WATSON, R.: Frequency Response Capability of Full Converter Wind Turbine Generators in Comparison to Conventional Generation, IEEE Trans. Power Systems 23 No. 2 (May 2008), 649-656.

[11] KEUNG, P.-K.-LI, L.-BANAKAR, H.-OOI, B. T. : Kinetic Energy of Wind-Turbine Generators for System Frequency Support, IEEE Trans. Power Systems 24 No. 1 (Feb 2009), 279-287.

[12] GAUTAM, D. : Impact of Increased Penetration of DFIG Based Wind Turbine Generators on Rotor Angle Stability of Power Systems, PhD thesis, Arizona State University, 2010.

[13] DUVAL, J.-MEYER, B. : Frequency Behavior of Grid with High Penetration Rate of Wind Generation, in PowerTech 2009 Conf., Bucharest, Romania, June 28 - July 2, 2009, pp. 1-6.

[14] AKBARI, M.-MADANI, S. M.: Participation of DFIG Based Wind Turbines in Improving Short Term Frequency Regulation, in Proc. Electrical Engineering (ICEE) 18th Iranian Conf., Isfahan, Iran, May 11-13, 2010, pp. 874-879.

[15] MAURICIO, J. M.-MARANO, A.-GOMEZ-EXPOSITO, A.-RAMOS, J. L. M.: Frequency Regulation Contribution through Variable-Speed Wind Energy Conversion Systems, IEEE Trans. Power Systems 24 No. 1 (Feb 2009), 173-180.

[16] ANDERSON, P. M.-FOUAD, A. A.: Power System Control and Stability, 2nd edition, Wiley-IEEE Press, 2002.

[17] CLARK, K.-MILLER, N. W.-SANCHEZ-GASCA, J. J.: Modeling of GE Wind Turbine-Generators for Grid Studies, General Electric International, One River Road, Schenectady, NY, USA, 2010, Tech. Rep. version 4.5.
[18] MILLER, N. W.-SANCHEZ-GASCA, J. J.-PRICE, W. W.DELMERICO, R. W.: Dynamic Modeling of GE 1.5 and 3.6 MW Wind Turbine-Generators for Stability Simulations, in Proc. IEEE Power Eng. Soc. General Meeting, July 2003, pp. $1977-1983$.

[19] CIGRE Technical Brochure 328, Modeling and Dynamic Behavior of Wind Generation as it Relates to Power System Control and Dynamic Performance, August 2007.

[20] "PSS E 32.0, PSS E Model Library" Siemens Energy, Inc., Siemens Power Technologies International, Schenectady, NY, Revised June 2009.

[21] MILLER, N. W.-PRICE, W. W.-SANCHEZ-GASCA, J. J. : Modeling of GE Wind Turbine-Generators for Grid Studies, General Electric International, Inc., Schenectady, NY, Mar 2005, Tech. Rep. version 3.4b.

[22] Electric Power Research Institute (EPRI), Generic Models and Model Validation for Wind and Solar PV Generation, Technical Update, 2011.

23] KUNDUR, P.: Power System Stability and Control, Mc Graw-Hill, New York, 1993, Ch. 11.

[24] OSMIĆ, J.-KUŠLJUGIĆ, M.-BEĆIROVIĆ, E.-TOAL, D. : Analysis of Active Power Control Algorithms of Variable Speed Wind Generators for Power System Frequency Stabilization, Turkish Journal of Electrical Engineering, accepted, DOI: 0.3906/elk-1307-193 http://online.journals.tubitak.gov.tr/ openAcceptedDocument.htm?fileID $=386389 \&$ no $=74528$.

[25] BEĆIROVIĆ, E.-OSMIĆ, J.-KUŠLJUGIĆ, M.-PERIĆ, N. : Design of Model Reference Controller of Variable Speed Wind Generators for Frequency Regulation Contribution, EUROPMENT Conference, 2013 International Conference on Environment, Energy, Ecosystems and Development (EEEAD 2013), Venice, 28-30 September 2013.

Received 12 July 2014

Elvisa Bećirović was born in Konjic, Bosnia and Herzegovina. She received B.Eng. and M.Sc. degree in electrical engineering from the Faculty of Electrical Engineering, University of Sarajevo and University of Tuzla, respectively. Currently she is a $\mathrm{PhD}$ candidate at the Faculty of Electrical Engineering, University of Zagreb. She is working in the Department for Strategic Development in EPC Elektroprivreda $\mathrm{B} \& \mathrm{H}$.

Jakub Osmić was born in Biberovo Polje, Bosnia and Herzegovina. He is currently an associate Professor at the Faculty of Electrical Engineering, University of Tuzla. His research interests are: automation and robotics, robust control, power system operation and stability, computer control process.

Mirza Kušljugić was born in Tuzla, Bosnia and Herzegovina. He is currently a Professor in the Department of Power Systems Analysis at the Faculty of Electrical Engineering, University of Tuzla. His research interests are: power system analysis, power system dynamics and stability, energy efficiency.

Nedjeljko Perić was born in Dubravica, Bosnia and Herzegovina. He is currently a Professor in the Faculty of Electrical Engineering and Computing Zagreb, University of Zagreb Croatia. His research interests are: digital processing, process identification and process automation. 